\title{
O PRINCÍPIO DA FRATERNIDADE COMO MEIO DE TRANSFORMAÇÃO SOCIAL E INCLUSÃO DA PESSOA TRANSGÊNERO
}

\author{
Débora Cristina Portella Pinchemel ${ }^{1}$ \\ Diogo de Calasans Melo Andrade ${ }^{2}$
}

\section{RESUMO:}

$\mathrm{O}$ artigo se propõe analisar a fraternidade como instrumento de transformação social com potencial de satisfazer os direitos fundamentais, um caminho à inclusão dos transgêneros enquanto força construtiva para o reconhecimento da igualdade entre todos os seres humanos, sobretudo uma igualdade em dignidade. Como objetivo específico escolheu-se analisar a identidade de gênero tendo como recorte aqueles indivíduos que vivem suas identidades de gênero fora dos marcos sócio normativos tradicionalmente aceitos, elegeu-se ainda analisar se tal condição os preterem de exercer direitos constitucionalmente previstos como a liberdade, a igualdade, a segurança, o direito ao nome e o direito à identidade pessoal, pretende-se, ainda, analisar tal questão com base no Princípio da Fraternidade enquanto alternativa para uma nova forma de relacionamento entre a sociedade, o Estado e as pessoas "trans", enquanto elemento de transformação da sociedade, levando-se em consideração a dignidade da pessoa humana, preceito fundamental do nosso ordenamento. $\mathrm{O}$ método de abordagem utilizado na consecução dos objetivos foi o indutivo; o método de procedimento, ao seu turno, foi o monográfico; e a técnica de pesquisa eleita foi a documental e a bibliográfica.

Palavras-chave: Dignidade humana; fraternidade; identidade de gênero.

\section{THE PRINCIPLE OF FRATERNITY AS A MEANS OF SOCIAL TRANSFORMATION AND INCLUSION OF THE TRANSGENDER PERSON}

\begin{abstract}
:
The article proposes Analyzing the fraternity as an instrument of social transformation with the potential to satisfy fundamental rights, a path to the inclusion of transgenders as a constructive force for the recognition of equality among all human beings, especially an equality in dignity. As a specific objective, it was decided to analyze the gender identity by choosing as a cut-off those individuals, who live their gender identities outside the traditionally accepted socio-normative frameworks, it was also decided to analyze if such condition precludes them from exercising constitutionally foreseen rights such as freedom , equality, security, the right to a name and the right to a personal identity, it is also intended to analyze this issue on the basis of the Fraternity Principle as an alternative to a new form of relationship between society, State and people "Trans", as an element of transformation of society, taking into consideration the dignity of the human person, fundamental precept of our

\footnotetext{
${ }^{1}$ Mestranda em Direitos Humanos (UNIT 2018.2), especialista em Direito Constitucional Processual pela UFS (2002), Especialista em Direito Processual: suas grandes transformações pela UNAMA (2007), Bacharelado em Direito pela Universidade Tiradentes (1993), Procuradora do Município de Nossa Senhora do Socorro/SE.

2 Doutor em direito político e econômico pela Universidade Mackenzie. Mestre em direito, na área de constitucionalização do direito pela UFS. Professor titular da graduação e do mestrado e doutorado em direitos humanos do PPGD-UNIT. Líder do grupo de pesquisa "Novas tecnologias e o impacto nos Direitos Humanos" do mestrado em direito Humanos da UNIT, advogado.
} 
order. The method of approach used to achieve the objectives was the inductive one; the procedure method, in turn, was the monographic one; and the chosen research technique was the documentary and the bibliographical one.

Keywords: Human dignity; fraternity; gender identity

\section{INTRODUÇÃO}

O viver em sociedade reclama a regulamentação das condutas no intuito de se preservar uma convivência pacífica entre os seres humanos. Com esse intuito surge o Direito, a fim de aparar as arestas do conviver, disciplinando condutas, assegurando a fruição dos bens, impondo deveres, e, acima de tudo, para garantir o equilíbrio social, garantindo a liberdade.

A proteção dos direitos do homem obteve a atenção da comunidade internacional sobretudo após as grandes guerras, com a idealização e criação da Organização das Nações Unidas. Pretendeu-se regular as relações internacionais objetivando diminuir ou minorar conflitos entre os Estados soberanos. Em especial para a proteção da pessoa humana a comunidade internacional em interlocução contínua tem desenvolvido regras comuns de tratamento, impositivas à toda a comunidade que as sobrescreva.

No entanto, até o momento a tão sonhada pacificação social não ocorreu. Vislumbramos facilmente fragrantes de desigualdade econômica, discriminação social, cultural, étnica, sexual, de gênero, e descompromisso com a dignidade do outro, ainda estando distante o ideal de liberdade e igualdade, a humanidade se vê carente de algo que venha arrematar a teia social conduzindo a humanidade no caminho da convivência realmente harmônica. A promoção da dignidade humana no mundo inteiro fundamenta-se na necessidade de ser ela resguardada não só por seu valor inerente a qualquer ser humano, mas em virtude de a paz, para ser mantida, exigir o respeito aos direitos Humanos (FRANCO NETO, 2013, p. 257).

Diante de tal cenário observamos o processo de exclusão daquelas pessoas que não se enquadram na concepção preestabelecida pelo grupamento social como a "normalidade" por expressarem suas identidades de gênero fora dos marcos sócio-normativos culturalmente aceitos pelo homem branco, rico e heterossexual, que dita as regras de comportamento social moderno e contemporâneo. 
Além do desconforto e sentimento de inadequação com o próprio corpo as pessoas transgênero, que se identificam com o gênero oposto ao biológico: homens que se apresentam e comportam como mulheres e mulheres que se apresentam e comportam como homens, convivem com o desconforto social, não bastasse o sofrimento interno em descortinar a inteireza de seu ser, convive diuturnamente com o preconceito e violência de uma sociedade que, malgrado as normas estabelecidas de garantia da liberdade em todos os níveis e igualdade entre os indivíduos, não as concretiza adequadamente, negando-lhes das mais diversas formas seu direito à liberdade, a igualdade, a segurança, ao nome e à identidade pessoal.

Nesse momento nos voltamos à necessidade de uma sociedade fraterna como uma terceira via para construção de novos paradigmas, e, para tanto, deve-se abandonar o egocentrismo Kantiano voltado para a própria individualidade e escolha privada, visão excludente, e hedonista, e abraçar o pensamento voltado ao encontro de novos paradigmas de um homem em comunhão comunitária, e, consequentemente, numa visão humanista do Direito, propiciar a realização integral do tripé liberdade, igualdade e fraternidade, estampado no conhecido lema da Revolução Francesa de 1789.

Pretende-se no presente artigo, analisar a fraternidade como instrumento de transformação da sociedade com capacidade de, criando novas concepções e resgatando valores, promover o respeito e efetivação dos direitos fundamentais, em especial das pessoas transgênero, em observância do artigo $3^{\circ}$, incisos I e IV da Constituição Federal ${ }^{3}$. E assim, contribuir para uma visão fraterna, inclusiva, emancipadora e evolucionista do Direito.

\section{IDENTIDADE DE GÊNERO E SEXO, UMA CONSTRUÇÃO SOCIAL}

A Comissão Internacional de Direitos Humanos entende o conceito de sexo como uma construção social e que "a atribuição de sexo não é um fato biológico inato; em vez disso, as pessoas recebem um sexo socialmente ao nascer, com base na percepção que os outros têm de

\footnotetext{
${ }^{3}$ Art. $3^{\circ}$ Constituem objetivos fundamentais da República Federativa do Brasil: I - construir uma sociedade livre, justa e solidária; (...) IV - promover o bem de todos, sem preconceitos de origem, raça, sexo, cor, idade e quaisquer outras formas de discriminação.
} 
seus genitais". Assim sendo a classificação das pessoas em sexos é uma decisão social e, portanto, um resultado de uma leitura ideológica dos corpos humanos, desde antes de seu nascimento, mais que uma verdade científica.

Por sua vez define identidade de gênero como "a experiência interna e individual do gênero como cada pessoa sente profundamente, que pode ou não corresponder ao sexo atribuído ao momento do nascimento, incluindo a experiência pessoal do corpo (o que poderia envolver Modificação da aparência ou da função corporal através de meios médicos, cirúrgicos ou outros, desde que seja livremente escolhidas) e outras expressões de gênero, incluindo vestuário, modos de falar e maneiras" (tradução livre). ${ }^{4}$

A identidade de gênero não é determinada por transformações corporais, intervenções cirúrgicas ou tratamento médico, é algo interno, individual, psicológico. E, quando se pretende escrever a respeito de temas tão caros ao sujeito, como soam ser aqueles que possuem "ligação medular" com a identidade da pessoa, deve-se começar pelo melhor lugar: o começo (BUTLER, 2015).

O que se deseja exprimir é que, desde sua concepção o indivíduo é idealizado, por seus pais e família. A simples pergunta em uma ultrassonografia sobre o "sexo" biológico da criança a ser gestada já trás toda uma carga de expectativas e direcionamentos que rotularão esse ser prima facie, seguindo com ele boa parte, senão toda a vida, levando-o a atuar de acordo com os padrões de determinado gênero. Butler (BUTLER. In: LOURO, 1999, p. 35) argumenta que essa concepção inaugura um processo de "fazer" desse um corpo feminino ou masculino, num processo baseado em características físicas que são vistas como diferenças e às quais se atribui significados culturais. Para ela, afirma-se e reitera-se uma sequência que de muitos modos já está consagrada, a sequência sexo-gênero-sexualidade. Essa, para alguns, é uma viagem tortuosa "como um corpo que importa, o sujeito se verá obrigado a obedecer às normas que regulam sua cultura" (BUTLER. In: LOURO, 1999, p 38).

O gênero só existe na prática, na experiência, e sua realização se dá mediante reiteração cujos conteúdos são interpretações sobre o masculino e o feminino (...). $\mathrm{O}$ ato de por uma roupa, escolher uma cor, acessórios, o corte de cabelo, a forma de andar, enfim a estética e a estilística corporais são atos que fazem o gênero, que

\footnotetext{
${ }^{4}$ Principios de Yogyakarta. Princípios sobre a aplicação da legislação internacional de direitos humanos em relação à orientação sexual e a identidade de gênero, nota de rodapé n. 1. Disponível : https:// yogyakartaprinciples.org/principles-sp/, acesso em: 20 jun. 2019. "Se entiende por identidad de género la profundamente sentida experiencia interna e individual del género de cada persona, que podría corresponder o no con el sexo asignado al momento del nacimiento, incluyendo el sentido personal del cuerpo (que, de tener la libertad para escogerlo, podría involucrar la modificación de la apariencia o la función corporal a través de medios médicos, quirúrgicos o de otra índole) y otras expresiones de género, incluyendo el vestido, el modo de hablar y los amaneramientos."
} 
viabilizam e estabilizam os corpos na ordem dicotomizada dos gêneros.( BENTO, 2004, cit. p. 144)

Mas o corpo físico não é a única variante que determina o gênero de uma pessoa, posto que, o que culturalmente nos é passado em muito contribui para a formatação do ser enquanto pessoa. Nossa individualidade é invadida e moldada por conceitos pré concebidos do agir e posicionar numa concepção dicotômica de homem/macho/pênis e mulher/fêmea/vagina, desconsiderando-se a possibilidade de outras configurações. Sequer se concebendo a possibilidade de alguém, subversivamente, tentar rompe-la.

Judith Butler, argumenta que o sexo, tido como verdade biológica anterior ao discurso, em verdade se constitui através dos próprios discursos sociais que atribuem a determinadas partes do corpo humano um valor simbólico específico. Da mesma que o gênero se constitui através de performances que produzem um estatuto ontológico generificado, o sexo constituise através da cultura (BUTLER, 2007). ${ }^{5}$

\begin{abstract}
Colocar em questão conceitos como o gênero, mesmo que signifique muitas vezes entrar em terrenos difíceis, ainda representa uma problematização mais simples - ou mais fácil de se realizar - do que questionar conceitos como corpo e sexo. E a dificuldade já começa em colocar esses últimos como conceitos, como produções (e produtores) do discurso. Os obstáculos talvez estejam relacionados mesmo àquela forma rígida de oposição natureza/cultura, em que corpo e sexo corresponderiam a dados do primeiro campo e gênero ao segundo. Essa forma que é a que também separa corpo e mente também inspirou o feminismo, que na separação sexo/gênero recusou falar do corpo ou o excluiu da teorização. Esse, natureza, ou era esquecido como modo de se evitar um determinismo biológico, ou era exaltado como lugar de essência do feminino. Mas ao recusar o corpo, o feminismo deixa-o nas mãos das produções discursivas, deixa-os nas mãos da biologia produzida hegemonicamente. Desfazer essas separações, ou melhor, aproximá-las é necessário para se reconhecer que campos como o da biologia/medicina não são campos de mera descrição, mas áreas de conhecimento que produzem significado sobre os corpos e sua humanidade (GOMES, 2017).
\end{abstract}

Mas como o homem é um ser em contínuo desenvolvimento, suas inquietações, quando exteriorizadas ganham corpo e agregam semelhantes, tendo como ponto de partida as desigualdades, traço presente na maioria das sociedades, fundada na natureza diferenciada entre os sexos, o movimento feminista, se contrapondo à opressão do feminino, iniciou uma ampla crítica do mundo social.

\footnotetext{
5 “ ¿en qué medida las practicas reguladoras de la formacion y la separacion de género determinan la identidad, la coherencia interna del sujeto y, de hecho, la condicion de la persona de ser identica a si misma? ¿En qué medida la "identidade" es un ideal normativo mas que un aspecto descriptivo de la experiencia?"
} 
As ideias gestionadas pelas Teorias Feministas e plantadas pela Teoria "Queer"6 causaram uma mudança paradigmática na concepção contemporânea de sujeito de direitos, pois a Ciência Jurídica, ao determinar quem seriam as pessoas aptas a exercerem direitos, o fez baseando-se apenas na ideia da diferença sexual entre homens e mulheres, não reconhecendo todas as possibilidades identitárias, agora reivindicadas pelo movimento "Queer", que podiam ser encontradas dentro do espectro das masculinidades e das feminilidades. A consequência dessa mudança, foi a construção de uma identidade coletiva que, a exemplo dos movimentos gay e lésbico, passaria a se reunir para designar uma agenda comum e então reivindicar direitos. A personalidade jurídica que foi consignada pelo legislador brasileiro, com base apenas na diferença sexual, ganharia um novo incremento, que estaria baseado na ideia de identidade, e essa identidade responderia à forma como o sujeito se autoreconhece, assim como à forma como o outro enxerga esse mesmo sujeito. (CAMPOS, 2018. cit. p.212.)

Dentro do contexto das afirmações de Simone de Beauvoir, "ninguém nasce mulher: torna-se mulher" (BEAUVOIR, 2009) ${ }^{7}$ a experiência transgênero rompe a ligação entre sexo/gênero/desejo e revela os acanhados limites do sistema binário assentado no corposexuado. Os olhares e certezas habituados ao mundo dividido em feminino/mulheres/vagina e masculino/homem/pênis ficam heterogêneos, confundem-se perante corpos que cruzam os limites estabelecidos do masculino/feminino e atrevem-se a reivindicar uma identidade de gênero em oposição àquela informada pela genitália (BENTO, 2008), mas sentida e percebida em sua psique como o lugar exato de se existir e expressar. ${ }^{8}$

Assim transgressores de convencionalidades que não elegeram, imbuídos do espírito de liberdade seguem a vida em luta pelo reconhecimento de sua condição de humano, livre, cidadão, iguais em direitos e deveres numa sociedade plural onde almejam seja perceptível essas pluralidades/desigualdades, reivindicando seu direito constitucional à liberdade e tratamento igualitário.

\footnotetext{
${ }^{6}$ Queer é uma palavra que no uso da língua inglesa pode referir-se tanto a sujeitos masculinos como a sujeitos femininos, e por extensão, a todas e cada uma das combinações derivadas da dicotomia de gênero que se possa imaginar, ou que se possa articular na prática cotidiana de comunidades marginais, em relação à heterossexualidade. Nesse sentido, queer é mais do que a soma de gays e lésbicas, inclui esses dois grupos e a muitas outras figuras identitárias construídas nesse espaço marginal (transexuais, transgêneros, travestis, etc) uma vez que se refere à inclusão de todas aquelas que podem proliferar em seu seio.

${ }^{7} \mathrm{Na}$ teoria da autora francesa, o homem é o sujeito, o sujeito abstrato, não-corpo. A mulher é o outro do homem, corpo a que se dá sentido pelo desejo masculino. Tal teoria, como já dito, pressupõe dois corpos dimorficamente diversos a que se imprimem os significados do masculino e feminino. E é essa pressuposição que precisa e pode ser colocada em questão: a leitura dos corpos como "naturalmente" dimórficos. (Camila de Magalhães Gomes) 8 “entende-se por normas de gênero as idealizações que estabelecerão os domínios da masculinidade e feminilidade apropriadas e impróprios e que estão fundamentadas no dimorfismo ideal e na complementaridade heterossexual dos corpos. O dimorfismo, a heterossexualidade e as idealizações serão as bases que constituirão o que Butler designou por "normas de gênero" e que terão como finalidade estabelecer o que será inteligivelmente humano e o que não, o que se considerará "real" e o que não, delimitando o campo ontológico no qual se pode conferir aos corpos expressão legítima.” (BUTLER, 1999).
} 


\section{DISCRIMINAÇÃO, DOR, PRECONCEITO. RESPEITO, INCLUSÃO}

Buscam serem respeitados, saem da invisibilidade buscando o reconhecimento de sua dignidade com fundamento nos direitos a todos garantidos como fundamentais e fundantes de um Estado democrático. O reconhecimento e proteção dos direitos do homem estão na base das constituições democráticas modernas, como garantia do exercício da liberdade e igualdade. E, não poderia ser diferente, a dignidade assim compreendida, legitima o Direito e se traduz como fundamentação principal do Estado e de toda a sociedade desenvolvida.

A garantia dos direitos fundamentais é requisito e condição essencial para que as democracias sejam consolidadas e, assim, as pessoas possam viver plenamente a promessa constitucional de suas dignidades enquanto seres humanos. Em comum a esses direitos, aspectos intrínsecos da vida social há, no Brasil, a garantia de sua observância e defesa pelo Estado Democrático de Direito, através de vários Princípios constitucionais fundamentais, dentre os quais a dignidade da pessoa humana, fundamento de nossa República, consagrado no artigo $1^{\circ}$, inciso III da Constituição Federal ${ }^{9}$.

Uma das maneiras encontradas juridicamente para consagrar a dignidade do indivíduo pelo legislador foi através do estabelecimento de sua personalidade jurídicamente consignada, cujos institutos vem sendo modernizadas modernizados seguindo tendência internacional, visando a garantia do direito ao nome e à identidade pessoal do indivíduo, com, ao menos, a possibilidade de mudança e adequação ao gênero com o qual se identifica nos registros civis, todavia, esses posicionamento normativo e jurisprudencial, além de espelhar-se exclusivamente no binário (masculino/feminino, homem/mulher) apenas garante parte da fruição dos direitos das pessoas transgênero, seu direito à liberdade, igualdade, segurança, por exemplo, está intimamente ligado à maneira que o corpo social absorve e incrementa a aceitação do "eu" individual. Mais que um problema técnico-jurídico, a discriminação e o preconceito são problemas culturais, que devem ser transpostos com o respeito ao autoreconhecimento do sujeito e suas subjetividades.

Sendo a dignidade humana um conceito valioso e importante da interpretação constitucional, tende a ocupar importante papel na fundamentação e resolução de questões

\footnotetext{
${ }^{9}$ Art. $1^{\text {o }}$. A República Federativa do Brasil, formada pela união indissolúvel dos Estados e Municípios e do Distrito Federal, constitui-se em Estado Democrático de Direito e tem como fundamentos: (...) III - a dignidade da pessoa humana.
} 
moralmente relevantes e complexas, o princípio da Dignidade Humana reforça esta nova perspectiva de garantia da dignidade individual deslocando a discussão do direito ao corpo para o direito ao desenvolvimento da personalidade da pessoa transexual. A adequação do nome e do sexo civil à identidade psicossocial da pessoa propicia a completude do ser, permitindo-o ser, sentir, se expressar, agir e ser conhecido e reconhecido na sociedade pelo que é.

Não obstante seu grande apelo moral, em sendo um conceito vago ela (dignidade da pessoa humana) adquire a feição de seu intérprete/aplicador, como leciona Barroso (2014. p. 10): “em termos práticos, a dignidade como conceito jurídico, frequentemente funciona como um mero espelho, no qual cada um projeta os seus próprios valores", valores estes construídos no convívio social e extraídos das raízes de um povo. O reconhecimento jurídico de sua identidade de gênero além de garantia do princípio da liberdade também se revela promotor da dignidade da pessoa transexual, aquela dignidade definida por Ingo Wolfgang Sarlet.

Temos por dignidade da pessoa humana a qualidade intrínseca e distintiva de cada ser humano que o faz merecedor do mesmo respeito e consideração por parte do Estado e da comunidade, implicando, neste sentido, um complexo de direitos e deveres fundamentais que assegurem a pessoa tanto contra todo e qualquer ato de cunho degradante e desumano, como venham a lhe garantir as condições mínimas para uma vida saudável, além de propiciar e promover sua participação ativa correponsável nos destinos da própria existência e da vida em comunhão dos demais seres humanos. (SARLET, 2012)

As Nações Unidas já afastam e repudiam qualquer tipo de discriminação, como se observa inclusive definindo cabalmente o que seja discriminação de gênero no Princípio de Yogyakarta número 2

La discriminación por motivos de orientación sexual o identidad de género incluye toda distinción, exclusión, restricción o preferencia basada en la orientación sexual o la identidad de género que tenga por objeto o por resultado la anulación o el menoscabo del reconocimiento, goce o ejercicio, en igualdad de condiciones, de los derechos humanos y las libertades fundamentales. La discriminación por motivos de orientación sexual o identidad de género puede verse y por lo común se ve agravada por la discriminación basada en otras causales, incluyendo el género, raza, edad, religión, discapacidad, estado de salud y posición económica. ${ }^{10}$

\footnotetext{
${ }^{10}$ Principios de Yogyakarta. Principios sobre a aplicação da legislação internacional de direitos humanos em relação à orientação sexual e a identidade de gênero, princípio n. 2.

"A discriminação com base na orientação sexual ou identidade de gênero inclui qualquer distinção, exclusão, restrição ou preferência baseada na orientação sexual ou identidade de gênero que tenha como objetivo ou resultar na anulação ou prejuízo do reconhecimento, gozo ou exercício, em igualdade de condições, dos direitos humanos e das liberdades fundamentais. A discriminação com base na orientação sexual ou identidade de gênero pode ser vista e geralmente é composta por discriminação baseada em outros motivos, incluindo sexo, raça, idade, religião, deficiência, estado de saúde e status econômico."(tradução livre)
} 
De tal forma, podemos afirmar com base nas vertentes da proteção internacional da pessoa humana, segundo Cançado Trindade (2003, p.24), que o exame da questão é realizado dentro da perspectiva integral dos direitos da pessoa humana, o reconhecimento legítimo da comunidade internacional com a promoção e proteção dos direitos humanos por todos, o que acarreta obrigações erga omnes, um compromisso internacional de prevalência dos Direitos Humanos atual e para a posteridade. Ademais destaca a DUDH que "todo ser humano tem deveres para com a comunidade, na qual o livre e pleno desenvolvimento de sua personalidade é possível"11.

Observa-se o binômio "respeitar/fazer respeitar", no sentido de que as obrigações assumidas pelos Estados Partes abrangem o dever incondicional de assegurar o cumprimento das disposições dos tratados de direitos humanos por todos os seus órgãos, agentes e todas as pessoas sujeitas a sua jurisdição, e, ainda, o dever de assegurar o respeito daquelas disposições por todos, inclusive pelos demais Estados Partes (BARROSO, 2014, p.21).

\section{A FRATERNIDADE ENQUANTO CAMINHO PARA CONCRETIZAÇÃO MULTIDIMENSIONAL DOS DIREITOS HUMANOS}

A Constituição pátria, estabelece contornos jurídicos de participação da sociedade, com reconhecimento das identidades de seus cidadãos, sentido já exposto a partir do compromisso preambular de uma sociedade fraterna, garantindo uma condição de igualdade em dignidade. De sorte que se faz necessário avançar trilhando o caminho para a solução dos conflitos sociais, retomando a tríade revolucionista francesa (liberdade, igualdade, fraternidade), e, entendendo a Fraternidade como categoria jurídica, e, seguindo a evolução lógica do constitucionalismo avançar em interpretações mais conectadas com o progresso de uma sociedade mais livre, e igualitária em sua heterogeneidade, buscando na fraternidade o direcionamento para um futuro melhor, coisa que já observamos no dizer de Machado o constitucionalismo contemporâneo evoluiu do liberal para o social, e deste para o humanista, atingindo, na atual quadra da história, o estágio fraternal (MACHADO, 2017, a). Uma sociedade fraterna é uma sociedade sem preconceitos e pluralista, assegurada a dignidade de todos e de qualquer um

\footnotetext{
${ }^{11}$ Declaração Universal dos Direitos do Homem, artigo 29.
} 
A fraternidade então deve ser entendida não apenas como um conceito, mas como um Princípio que está na origem de um comportamento, uma relação que deve ser instaurada com outros seres humanos, agindo "uns em relação aos outros", o que implica também a dimensão da reciprocidade (AQUINI, 2008, p.137), alargando a ideia de que todo ser humano deve ser tratado como qualquer outro ser humano, imergindo daí o dever que todos tem para com a comunidade, a evocação de tais deveres evidencia que cada um deve prestar sua contribuição na construção da sociedade (AQUINI, 2008, p.133/134). Quanto mais universais forem os direitos, mais se assenta o sentimento do dever de respeitá-los, como alicerce bem construído de uma sociedade justa e fraterna. Não se pode dissociar a plena realização dos direitos fundamentais dos deveres, pois aqueles dependem do reconhecimento destes (MACHADO $2017, b)$.

por conseguinte, os que reivindicam os próprios direitos, mas se esquecem por completo de seus deveres ou lhes dão menor atenção, assemelham-se a quem constrói um edifício com uma mão e, com a outra, o destrói. (João XXIII - Pacem in terris n. 30)

Assim observamos que a responsabilidade é elemento da fraternidade ao exigir o reconhecimento do outro, o respeito pelos direitos humanos, responsabilizando cada indivíduo pelo outro e, consequentemente, pelo bem da comunidade promovendo a busca de soluções para aplicação dos direitos humanos que não passam necessariamente pela ação do Estado, ampliando assim o rol de sujeitos sobre os quais recai a responsabilidade pelo desenvolvimento e pelo dever de cooperação, transformando os atores da sociedade civil passam de meros expectadores das ações do Estado a protagonistas das soluções necessárias ao bem estar social (MACHADO, 2017, b). Ao responder pesquisa promovida pela UNESCO em 1947 para Comentar o esboço da Declaração Universal dos Direitos do Homem Mahatma Gandhi assim se posicionou:

I learn form my illiterate but wise mother that all rights to be deserved and preserved came from duty well done. Thus the very right to live accrues to live as only when we to the duty of citizenship of the world. From this only fundamental statement, perhaps it is a easy enought to define the duties of man and woman and correlate every right to some corresponding duty to be frist performed. Every other right can be shown to be a usurpation hardly worth fighting for. (Gandhi - Unesco, 1949, p.3) $)^{12}$.

\footnotetext{
12 “Aprendi com minha mãe analfabeta, mas sábia, que todos os direitos a serem merecidos e preservados vinham do dever bem feito. Assim, o próprio direito de viver acumula-se para viver apenas quando nos dedicamos ao dever de cidadania do mundo. A partir dessa única afirmação fundamental, talvez seja fácil definir os deveres do homem e da mulher e correlacionar todos os direitos a algum dever correspondente, que devem ser
} 
A fraternidade é composta de três elementos, solidariedade, liberdade e igualdade, queremos dizer que ela se apresenta de maneira em que todos são agentes ativos no pleno desenvolvimento de sua responsabilidade por outem devem todos trabalhar para desenvolver os direitos humanos, tanto individualmente quanto em comunidade, reconhecendo-se a universalidade dos direitos, respeitando-se a diferença e o pluralismo numa relação de reciprocidade, já que o indivíduo só existe em razão de seu semelhante.

$\mathrm{Na}$ fraternidade abandona-se o antropocentrismo Kantiano para abraçar a pluralidade do corpo social, reconhecendo a responsabilidade de todos e de cada um para a construção de uma sociedade livre, igual em suas diferenças e fraterna. Segundo Hans Jonas ${ }^{13}$ a responsabilidade é "imperativo ético para que cada pessoa possa guiar-se no exercício da cidadania assegurando a existência humana e de todas as formas de vida existentes". Responsabilidade esta determinada pelos fins das ações humanas - todos são responsáveis pelos atos e pelos efeitos dos atos praticados em sociedade - e pela corresponsabilidade pela vida humana.

A fraternidade representa uma atenção incondicional ao outro, pressupondo, além disso, que a liberdade de um não pode ser realizada sem observar-se a liberdade de outrem, e, assim sendo torna ambos corresponsáveis pela liberdade recíproca. Vai além da solidariedade já que esta não considera a paridade e reciprocidade das relações. Enquanto conceito ético significa encontrar-se a si mesmo nos demais, é o verdadeiro sentido de irmandade com o outro enquanto pessoa, enquanto membro de uma mesma família: a humanidade. Também não se revela um dever específico, mas a exigência de que qualquer pessoa, podendo agir, procure tornar efetivos os direitos de qualquer um. Um verdadeiro dever implícito de ação, dentro das condicionantes específicas de cada um.

\footnotetext{
Reconhecer o outro como irmão é afirma-lo como igual a si mesmo e, portanto, o outro tem os mesmos direitos e os mesmos deveres.

A reciprocidade exige, dentro do possível, a estrita simetria entre as pessoas: não há direitos sem deveres, não há deveres sem direitos.

A reciprocidade como elemento da Fraternidade é particularmente urgente na chamada "crise do Estado Social". O Estado Social tradicional estruturou-se segundo uma lógica puramente solidária, em que o Estado assumia a responsabilidade pela satisfação das carências dos cidadãos. (...)
}

realizados em primeiro lugar. Qualquer outro direito pode ser mostrado como uma usurpação pela qual dificilmente vale a pena lutar. (tradução livre)

${ }^{13}$ Responsabilidade e heurística do temor em Hans Jonas (Paulo César Nodari) 
Os direitos sociais, nesta perspectiva, são vistos como contratos [reciprocidade] entre o beneficiário e a sociedade, e não um direitos (do desempregado) ou um dever (da sociedade) unilaterais.

(...) a atitude contrária à reciprocidade é a parcialidade, ou seja, a preferência arbitrária por si mesmo, que consiste em exigir dos demais aquilo que não se está disposto a fazer a favor deles. Ou na terminologia empregada até aqui: a parcialidade é querer para si os direitos e para os outros os deveres (BARZOTTO, 2018, p.85).

A inclusão social fomentada no artigo $3^{\circ}$, inciso IV da Constituição Federal, é a correta expressão dessa fraternidade, demonstrando respeito humano solidário relacionado diretamente com o Princípio da Fraternidade e com a função do direito em promover a pessoa humana, lembrando que a conscientização é um processo de mútua cooperação de todos. O comprometimento e a participação podem proporcionar a justiça social distributiva visando o pleno exercício da cidadania, já que o direito serve para regulamentação de condutas visando propiciar as relações intersubjetivas entre os seres humanos, levando-os a viverem uns com ou outros e não apesar dos outros, e na defesa de práticas fraternas, entender que um é responsável pelo outro, ou no dizer de Britto,

\begin{abstract}
A Fraternidade é o ponto de unidade a que se chega pela conciliação possível entre os extremos da Liberdade, de um lado, e, de outro, da Igualdade. A comprovação de que, também nos domínios do Direito e da Política, a virtude está sempre no meio (medius in virtus). Com a plena compreensão, todavia, de que não se chega à unidade sem antes passar pelas dualidades. Este, o fascínio, o mistério, o milagre da vida (BRITTO, 2007, p. 98).
\end{abstract}

\title{
5 CONSIDERAÇÕES FINAIS
}

Assentado sobre a ideia de que cada ser humano possui um valor intrínseco, único e essencial, desfrutando de uma posição especial no universo, o reconhecimento e proteção dos direitos do homem estão na base das constituições democráticas modernas, como garantia do exercício da liberdade e igualdade. E, não poderia ser diferente, a dignidade assim compreendida, legitima o Direito e se traduz como fundamentação principal do Estado e de toda a sociedade desenvolvida.

De tal sorte a expansão dos direitos fundamentais neste momento de transformações culturais vertiginosas, com grandes mudanças de paradigmas, reclama, também o reconhecimento da fraternidade como força motriz de transformações essenciais para a vida 
em comunidade. Com o reconhecimento da importância da dignidade da pessoa humana vem-se afirmar a proteção jurídica da pessoa através da exaltação dos direitos à individualidade íntima e social, propiciando o alargamento da titularidade do direito fundamental ao livre desenvolvimento da personalidade e a autodeterminação, a proteção conferida pelo direito deve tutelar as múltiplas situações existenciais, procurando assim efetivar no mundo jurídico a realização da pessoa enquanto possuidora de direitos e deveres ante e perante o corpo social.

A Fraternidade deve ser considerada um princípio jurídico capaz de agir como instrumento regulador das relações sociais, destacando-se pela concretização da igualdade entre todos promovendo uma relação sem diferenças na busca da efetivação dos Direitos Fundamentais, equilibrando as relações e modificando o tratamento dado, sobretudo, aos direitos das pessoas transexuais, contribuindo para a mudança de paradigma necessária à concretude do respeito ao livres desenvolvimento e expressão da personalidade de cada ser humano de acordo com a sua subjetividade.

Caminhamos o bom caminho quando deixamos a fraternidade nos guiar, "pois o que marca as pessoas não é serem afetadas na sua autopreservação e auto interesse, mas a Fraternidade - responsabilidade recíproca - que emerge quando o ser humano não pode mais fundar sua vida no controle que ele tem sobre seu ambiente, mas é obrigado a fundá-la sobre a relação com o outro ser humano" (BARZOTTO, 2018. 79-89). E assim contribuir para uma sociedade realmente justa, pacífica e igualitária.

\section{REFERÊNCIAS}

AQUINI, Marco. Fraternidade e direitos humanos. In: $\mathrm{O}$ princípio esquecido: A fraternidade na reflexão atual das ciências políticas / Antônio Maria Baggio (organizador); [traduções Durval Cordas, Iolanda Gaspar, José Maria de Almeida] - Vargem Grande Paulista, SP: Editora Cidade Nova, 2008. 127-151.

BARROSO, Luís Roberto. A dignidade da pessoa humana no Direito Constitucional contemporâneo: a construção de um conceito jurídico à luz da jurisprudência mundial/Luís Roberto Barroso. Tradução Humberto Laport de Mello, - 3. Reimpressão. Belo Horizonte: Fórum. 2014.

BARZOTTO, Luiz Fernando. Fraternidade: uma aproximação conceitual. In: Direito e Fraternidade: em busca da concretização / Organização [de] Carlos Augusto Alcântara 
Machado, Clara Cardoso Machado Jaborandy, Luciene Cardoso Bazotto. - Aracaju: EDUNIT, 2018. 79-89

BEAUVOIR, Simone. O segundo sexo. Trad. Sergio Milliet. $2^{\mathrm{a}}$ ed. Rio de Janeiro: Nova Fronteira, 2009.

BECKER, Patrícia Vilanova. Políticas de respeito à diversidade sexual e à igualdade de gênero na iniciativa privada: Uma análise a partir do projeto Freeda - espaços de diversidade. 2017. 86 f., il. Dissertação (Mestrado em Direito)—Universidade de Brasília, Brasília, 2017. Disponível em: http://repositorio.unb.br/handle/10482/31406 acesso em $22 / 06 / 2019$

BENTO, Berenice Alves de Melo. Da transexualidade oficial às transexualidades. In: Sexualidade e saberes: convenções e fronteiras Piscitelli, Adriana; Gregori, Maria Filomena; Carrara, Sérgio (orgs.)., Rio de Janeiro: Garamond, 2004, p. 143-172

Berenice Alves de Melo. O que é transexualidade. São Paulo: Brasiliense, 2008.

BRITTO, Carlos Ayres. O Humanismo como categoria constitucional. Belo Horizonte: Fórum, 2007.

BUTLER, Judith. Corpos que pensam: sobre os limites discursivos do sexo. In: LOURO, Guacira. O corpo educado - Pedagogias da sexualidade. Trad. Tomaz Tadeu da Sila. Belo Horizonte: Autêntica, 1999.

Judith, 1999. Gender Trouble: feminism and the subversion of identity. New York/London: Routledge.

, Judith. El género en disputa. El feminismo y la subversión de la identidad, Barcelona: Paidós, 2007

, Judith. Sem medo de fazer gênero. in: Folha de São Paulo (2015). Disponível em: $\overline{<h t t p: / / w w w 1 . f o l h a . u o l . c o m . b r / i l u s t r i s s i m a / 2015 / 09 / 1683172-s e m-m e d o-d e-f a z e r-g e n e r o-~}$ entrevista-com-a-filosofa-americana-judith-butler.shtml> Acesso em 05. Fev. 2019.

CANÇADO TRINDADE, Antônio Augusto. As três vertentes da proteção internacional da pessoa humana: aproximações ou convergências entre os direitos humanos, o direito humanitário e o direito dos refugiados. In: Tratado de Direito Internacional dos Direitos Humanos. Vol. I. Porto Alegre: Sérgio Antônio Fabris Editor, 2003

CAMPOS, Ingrid Zanella Andrade, NETO, Clarindo Empaminondas de Sá. A cidadania sexual fraterna: por uma concepção de dignidade para as pessoas "trans". In Revista Jurídica - UNICURITIBA, vol. 01. № 50, Curitiba, 2018, pp. 209-243. Disponível em:

revista.unicuritiba.edu.br/index.php/RevJur/article/download/2549/1513, acesso em: 20/06/2019.

CORRÊA, S. O. E MUNTARBHORN, V. (orgs.). Princípios de Yogyakarta: princípios sobre a aplicação da legislação internacional de direitos humanos em relação à orientação 
sexual e identidade de gênero. Disponível em: $<$ http://www.clam.org.br/pdf/principios_de_yogyakarta.pdf >. Acesso em: 12 jun. 2019.

EUGENIO, Gabriel Soares. Pelo direito de existir além das barreiras patologizantes: a experiência das pessoas trans em uma perspectiva argumentativa. 2018.140 f., il. Dissertação (Mestrado em Direito)—Universidade de Brasília, Brasília, 2018. Disponível em:. http://repositorio.unb.br/handle/10482/32543. Acesso em 22/06/2019.

FRANCO NETO, Laercio Dias; BASTOS, Dafne Fernandez de. O Processo e o Direito Coletivo no Sistema Interamericano de Direitos Humanos: uma análise com base na jurisprudência internacional. Revista de Direito Internacional, v. 10, $\mathrm{n}^{\mathrm{o}}$ 2. 2013, p.250-261 Disponível em:

https://www.publicacoesacademicas.uniceub.br/rdi/article/download/2719/pdf acesso em 27/10/2018.

O'FLAHERTY, Michael. FISHER, John. Sexual Orientation, Gender Identy and International Human Rights Law: Contextualising the Yogyakarta Principles. Human Rights Law Review, Oxford University, P. 207-248, 2008.

CANÇADO TRINDADE, Antônio Augusto. As três vertentes da proteção internacional da pessoa humana: aproximações ou convergências entre os direitos humanos, o direito humanitário e o direito dos refugiados. In: Tratado de Direito Internacional dos Direitos Humanos. Vol. I. Porto Alegre: Sérgio Antônio Fabris Editor, 2003, p.24

GOMES, Camilla de Magalhães. Têmis Travesti: as relações entre gênero, raça e direito na busca de uma hermenêutica expansiva do "humano" no Direito. 2017. 234 f. Tese (Doutorado em Direito)-Universidade de Brasília, Brasília, 2017. Disponível em: http://repositorio.unb.br/handle/10482/23975 acesso em 22/06/2019.

MACHADO, Carlos Augusto Alcântara. A fraternidade como categoria jurídica: fundamento e alcance (expressão do constitucionalismo fraternal) / Carlos Augusto Alcântara Machado. - Curitiba: Appris, 2017.

MACHADO, Clara. O princípio Jurídico da Fraternidade: um instrumento para proteção dos direitos fundamentais transindividuais. 1. Ed. Rio de Janeiro: Lumen Juris, 2017.

PACEM IN TERRIS. Carta Encíclica do Sumo Pontífice Papa João XXIII aos veneráveis irmãos patriarcas, primazes, arcebispos, bispos e outros ordinários do lugar em paz e comunhão com a Sé Apostólica ao clero e fiéis de todo o orbe, bem como a todas as pessoas de boa vontade Disponível em: <http://w2.vatican.va/content/johnxxiii/pt/encyclicals/documents/hf_j-xxiii_enc_11041963_pacem.html.$\quad$ Acesso em: 20/06/2019.

SANTOS, Boaventura de Souza. Direitos Humanos, democracia e desenvolvimento / Boaventura de Souza Santos, Marilena Chaui. São Paulo: Cortez, 2013. 
SARLET, Ingo Wolfgang. A eficácia dos direitos fundamentais: uma teoria geral dos direitos fundamentais na perspectiva constitucional. $11^{\mathrm{a}} \mathrm{ed}$. Porto Alegre. Livraria do Advogado, 2012.

UNESCO, 1949. Human rights: comments and interpretations; a symposium edited by UNESCO, with an introduction by Jacques Maritain, p. 3. Disponível em: https://unesdoc.unesco.org/ark:/48223/pf0000155042, acesso em: 23/06/2019. 